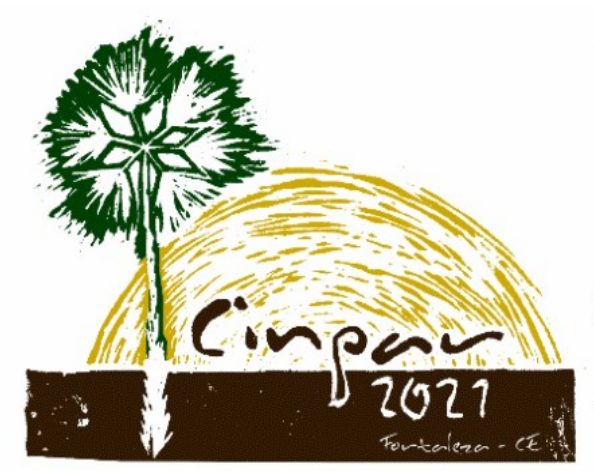

XVII Congresso Internacional sobre Patologia e Reabilitação das Construções

XVII Congreso Internacional sobre Patología y Rehabilitación de las Construcciones

XVII International Conference on Pathology and Constructions Rehabilitation

FORTALEZA (Brasil), 3 a 5 de junho de 2021 https://doi.org/10.4322/CINPAR.2021.092

\title{
Ensaio termográfico de edificação histórica: Igreja de Nossa Senhora da Conceição de Almofala
}

\section{Thermographic test of historical heritage: Igreja de Nossa Senhora da Conceição de Almofala}

\author{
Jennifer Braga LUZ, Ivna de Oliveira SILVEIRA, Marcos Andrew Rabelo SOEIRO \\ ${ }^{1}$ UNIFOR, Fortaleza, Brasil, luzbjennifer@gmail.com \\ ${ }^{2}$ UNIFOR, Fortaleza, Brasil, ivna.o.s@gmail.com \\ ${ }^{3}$ UNIFOR, Fortaleza, Brasil, marcos@duosestruturais.eng.br
}

\begin{abstract}
Resumo: A termografia por infravermelho tem sido utilizada na identificação de patologias, como fissuras, umidade, descolamento de revestimento, dentre outros. Por ser uma técnica não intrusiva, que não causa danos na edificação, ela vem sendo utilizada de forma eficiente em países europeus para manutenção preventiva de patrimônios históricos. $O$ trabalho visa a utilização da termografia para identificação de elementos possivelmente danificados na Igreja de Nossa Senhora da Conceição de Almofala, em Itarema, no estado do Ceará. A edificação foi erguida no século XVIII, foi soterrada pela areia em 1897 e, passados mais de quarenta anos, os ventos a descobriram. Em 1980 foi tombada pelo IPHAN, levando-se a uma restauração em 1983. Este trabalho realizou pesquisa de campo para obtenção de termogramas da referida igreja, cujo procedimento baseou-se na revisão bibliográfica das normas e trabalhos científicos pertinentes ao tema. Através da análise dos termogramas, o trabalho concluiu que, apesar das limitações do método, é possível obter um panorama preliminar da situação da edificação. Desta forma, o trabalho ganha importância por contribuir com a análise de edificação de significativo valor cultural para a região e por fomentar o debate sobre a eficiência da termografia como meio de identificação de patologias.
\end{abstract}

Palavras-chave: Patrimônio. Patologia. Termografia.

\begin{abstract}
Infrared thermography has been used to identify pathologies, such as cracks, humidity, coating detachment, among others. As it is a non-intrusive technique, which does not cause damage to the building, it has been used efficiently in European countries for preventive maintenance of historical heritage. The work aims to use thermography to identify damaged elements in the Church of Nossa Senhora da Conceição of Almofala, in Itarema, in the state of Ceará. The building was erected in the 18th century, was buried under sand in 1897 and, after more than forty years, the winds discovered the building. In 1980 it was listed by IPHAN, leading to a restoration in 1983. This work resulted in field research to obtain thermograms from the church, whose procedure was based on the bibliographic review of the norms and scientific papers relevant to the theme. Through the analysis of thermograms, the work developed that, despite the limitations of the method, it is possible to obtain a preliminary overview of the situation of the building. In this way, the work gains importance for contributing to the analysis of edification of significant cultural value for the region and for promoting the debate on the efficiency of thermography as a means of identifying pathologies.
\end{abstract}

Keywords: Heritage. Pathologie. Thermography. 


\section{Introdução}

É sabido que o patrimônio histórico representa a identidade e cultura de um povo, sendo importante que haja esforços no sentido de assegurar sua permanência para usufruto das gerações presentes e futuras. Isso posto, com objetivo de contribuir para a preservação desse patrimônio, o presente trabalho visa a utilização da termografia para identificação de elementos possivelmente danificados na Igreja da Nossa Senhora da Conceição de Almofala, em Itarema, no estado do Ceará.

Os testes destrutivos tradicionais não são possíveis de se realizar na maioria dos edifícios históricos, uma vez que são procedimentos invasivos, que podem vir a danificar a edificação, por isso é necessário selecionar testes não destrutivos que permitam analisar a situação da edificação. Dentre os ensaios não destrutivos, destaca-se no presente trabalho o ensaio de termografia, que além de ser um ensaio não intrusivo, totalmente inofensivo ao patrimônio em estudo, alcança grande área em pouco tempo.

A termografia tem sido amplamente utilizada no continente europeu para fins de identificação de patologias, possuindo normas vigentes desde o ano de 1999, que orientam os procedimentos para realização do ensaio. No Brasil, o ensaio não é empregado com esta mesma frequência e carece de normas regulatórias específicas para executar o procedimento em edificações.

Apesar destas limitações, é possível realizar o ensaio baseando-se em parâmetros internacionais e referências bibliográficas de trabalhos correlatos ao tema. A cuidadosa interpretação dos resultados, pode levar a localização de áreas comprometidas, que deverão ser submetidas a uma posterior análise por meio de outros métodos.

\section{Revisão Bibliográfica}

Segundo Verati (2011) e Pelliazari (2006), citados por Abreu et al. (2012), a Inspeção Termográfica é uma técnica de inspeção não destrutiva realizada com a utilização de sistemas infravermelhos para a medição de temperaturas ou observação de padrões diferenciais de distribuição de calor, sendo baseada na medida da radiação eletromagnética emitida por um corpo a uma temperatura acima do zero absoluto, já que todos os objetos com temperatura acima de 0 Kelvin emitem radiação na faixa do infravermelho.

A NBR 15424 (2016) que trata das terminologias do ensaio termográfico, conceitua dois tipos de termografia: Ativa e Passiva. A técnica de inspeção termográfica ativa requer estímulo térmico adicional (fontes externas), podendo ser óptico, sônico (ultrassom), indutivo, micro-ondas ou outra forma de energia. A técnica de inspeção termográfica passiva mede a radiação infravermelha emitida pelos objetos sem a necessidade de estímulos térmicos adicionais. Nas edificações ocorre a predominância de trabalhos de termografia passiva, pelas dificuldades na excitação térmica externas, pelas dimensões do alvo e pela grande quantidade de energia necessária (HOLST, 2000).

Quando da avaliação térmica, Tavares (2006) explica que o esperado é obter uma distribuição uniforme da temperatura quando o material é homogêneo, ou seja, sem defeitos, mas quando há presença de falhas, a variação das propriedades no ponto em que elas estão presentes influencia na difusão do calor, o que ocasiona normalmente a queda da temperatura.

A imagem obtida a partir da radiação infravermelha emitida pelos objetos, em função de sua temperatura, recebe o nome de termograma e conforme explica a NBR 15424 (2016), esta imagem pode ser em tons de cinza ou diferentes cores, representando a temperatura aparente da superfície.

Quanto ao método de análise das imagens obtidas no monitoramento das edificações, pode ser quantitativo ou qualitativo. A análise qualitativa é considerada uma técnica da termografia infravermelha que fornece laudos instantâneos, pois o enfoque dela é o perfil e não os valores (ITC, 2014 apud SILVA et al. 2019), sendo uma comparação do valor relativo ao acesso local em relação a um ponto de referência, enquanto a análise quantitativa dos dados permite uma determinação precisa da temperatura de um ponto ou de uma região (BAGAVATHIAPPAN et al., 2013 apud SILVA et al. 2019).

Para Rocha e Povoas (2017) a termografia infravermelha se apresenta como uma técnica rápida, nãoinvasiva, sem contato, e que por estas característica, pode ser aplicada a grandes distâncias, sendo possível 
analisar e inspecionar grandes áreas em pouco tempo. Além disso, sua utilização torna-se bastante relevante para o estudo de patrimônios históricos, por seu caráter totalmente não invasivo, pois de acordo com Inagaki et al. (1999, apud TAVARES, 2006) o diagnóstico utilizando a tecnologia infravermelha é absolutamente inofensiva, seja a sistemas vivos, seja a equipamento e estruturas.

Cortizo et al. (2008) observa que na construção civil, esta técnica tem sido empregada para a detecção de vazamentos, inspeção térmica de entorno de novas obras e testes térmicos para conservação de patrimônio histórico. Em síntese, as técnicas de termografia permitem a visualização da edificação, possibilitando a identificação de anomalias e manifestações patológicas.

A identificação e quantificação de anomalias e manifestações patológicas em edificações com termografia é bem complexa, porque as diferenças de temperatura entre as zonas com e sem anomalia são relativamente pequenas, se comparadas com outras áreas da engenharia onde se estudam componentes e equipamentos que geram calor durante seu funcionamento. (BAUER e PAVÓN, 2015). Além disso, o clima, horário e local em que foi realizado o ensaio, exposição ao sol, sombreamento, acuracidade dos equipamentos utilizados, dentre outros fatores, podem influenciar o resultado obtido no termograma.

Segundo Cortizo et al. (2011), citado por Freitas et al. (2014), apesar de a técnica ser bastante difundida nos países europeus, graças ao grande acervo histórico, no Brasil sua utilização é relativamente nova, podendo ser motivada pela dificuldade de aplicação prática.

\section{Resultados}

No momento do ensaio, foram coletados os dados da temperatura, da umidade relativa do ar e velocidade do vento na cidade através do site weather.com. As informações estão listadas na Tabela 01:

\begin{tabular}{|c|c|c|c|c|}
\hline Data & Período & Temperatura & Umidade & Vento \\
\hline $21 / 12 / 2020$ & Matutino $10 \mathrm{~h}$ & $30^{\circ} \mathrm{C}$ & $63 \%$ & $27 \mathrm{~km} / \mathrm{h}$ \\
\hline $21 / 12 / 2020$ & Vespertino $14 \mathrm{~h}$ & $31^{\circ} \mathrm{C}$ & $59 \%$ & $27 \mathrm{~km} / \mathrm{h}$ \\
\hline
\end{tabular}

Tabela 01: Dados Climáticos Itarema-CE. Fonte: Weather.com (2020).

Em termograma obtido do centro da fachada em período matutino, observa-se na Figura 01 que o trecho em destaque apresenta temperatura inferior, se comparado às regiões adjacentes. Esta característica normalmente é justificada pela presença de água no local, pois considerando que a água tem calor específico mais elevado do que materiais comuns de construção, isto faz com que demore mais a esquentar e resfriar.
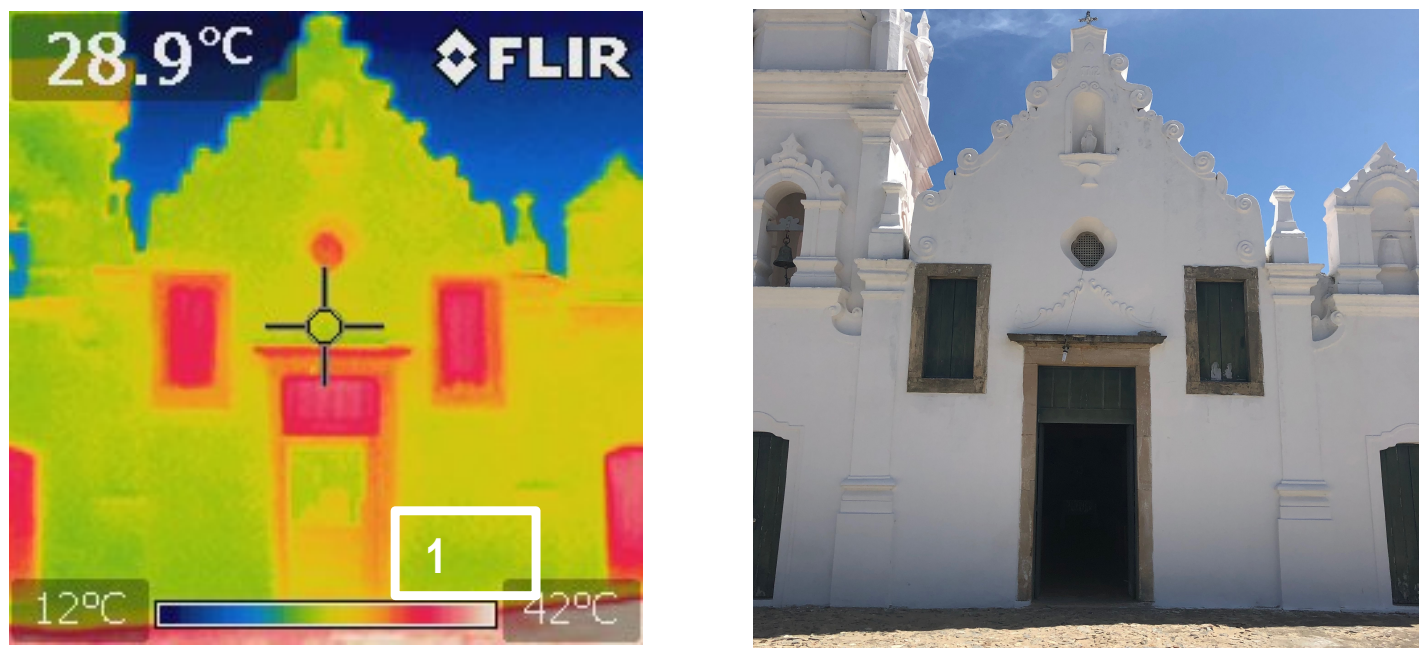

Figura 01 - Termograma e foto da parte central da fachada em período matutino. Fonte: Acervo pessoal. No entanto, a mesma região que anteriormente apresentava temperatura inferior, durante o período da tarde, apareceu no termograma com temperatura um pouco superior às das regiões adjacentes, conforme 
pode ser visto no destaque 1 da Figura 02. Além disso é possível identificar uma outra zona com temperatura mais elevada, conforme destaque 2 da Figura 02.

Este comportamento não é o esperado para regiões com presença de umidade, pois durante o dia, quando há presença de água, a evaporação causa uma redução da temperatura superficial nestas regiões.

Importante observar que Monteiro et al (2015) informa que houve intervenção realizada na Igreja em 1983 pelo Instituto Brasileiro de Patrimônio Histórico e Cultural (IBPC) e Fundação Nacional Pró-memória, em que as pinturas das paredes e esquadrias externas e internas tiveram tratamento prévio da alvenaria com selador antes de receber a pintura em locais de maior umidade e que atualmente a igreja recebe reparo anual relacionado à pintura.

Além disso, Coelho e Monteiro (2013) observam que desde que a igreja vem sendo acompanhada, vem se observando a presença de algumas manifestações patológicas, como infiltrações e salitre.

Diante do exposto, as zonas inferiores mais quentes não descartam a presença da umidade, pois pode estar associada a outra patologia, como deterioração, presença de microorganismos ou pode haver material com emissividade diferente que foi aplicado nas manutenções anuais.
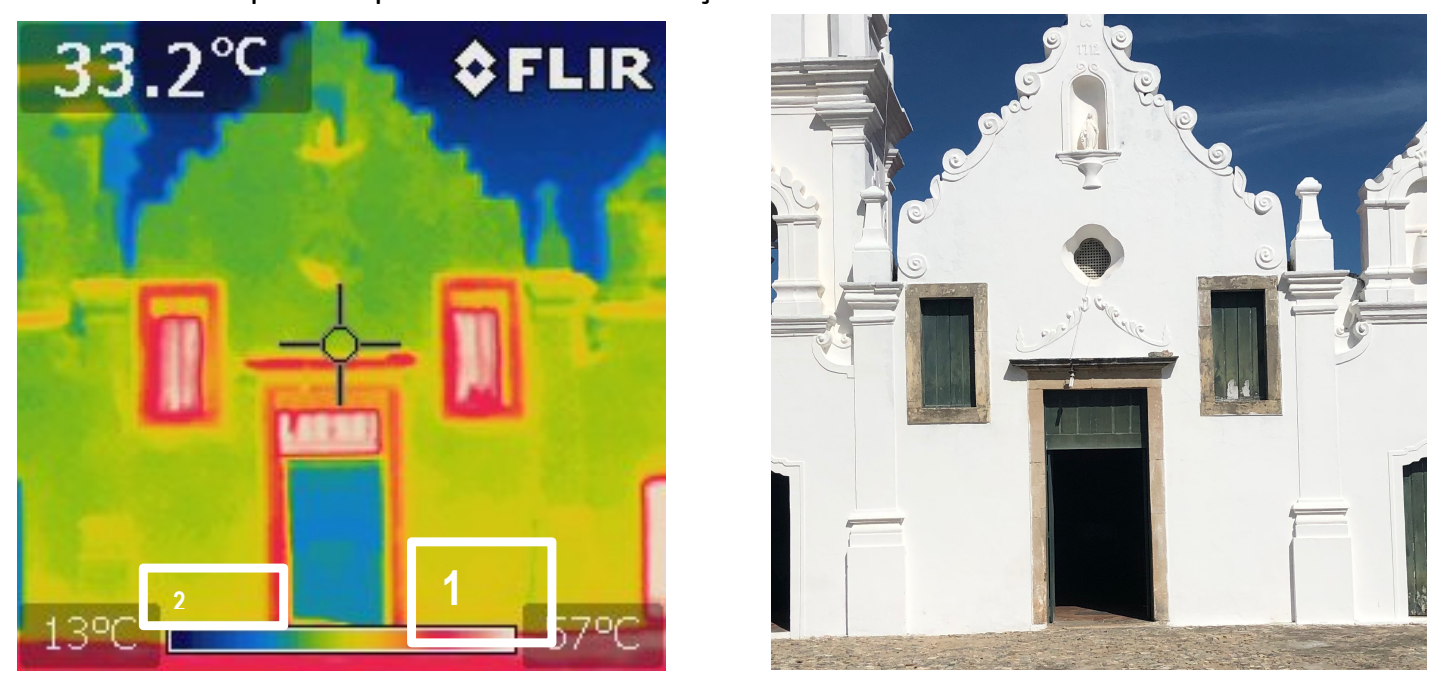

Figura 02- Termograma e foto da parte central da fachada em período vespertino. Fonte: Acervo pessoal. Ao focar a torre que fica na parte esquerda da fachada, avista-se fenômeno semelhante ao descrito anteriormente, em que a zona contida no destaque 01 da Figura 03 apresenta temperatura inferior às das zonas adjacentes no período da manhã. Ao entardecer, em que a fachada já teve considerável período de exposição solar, a zona passa a apresentar temperatura mais elevada.
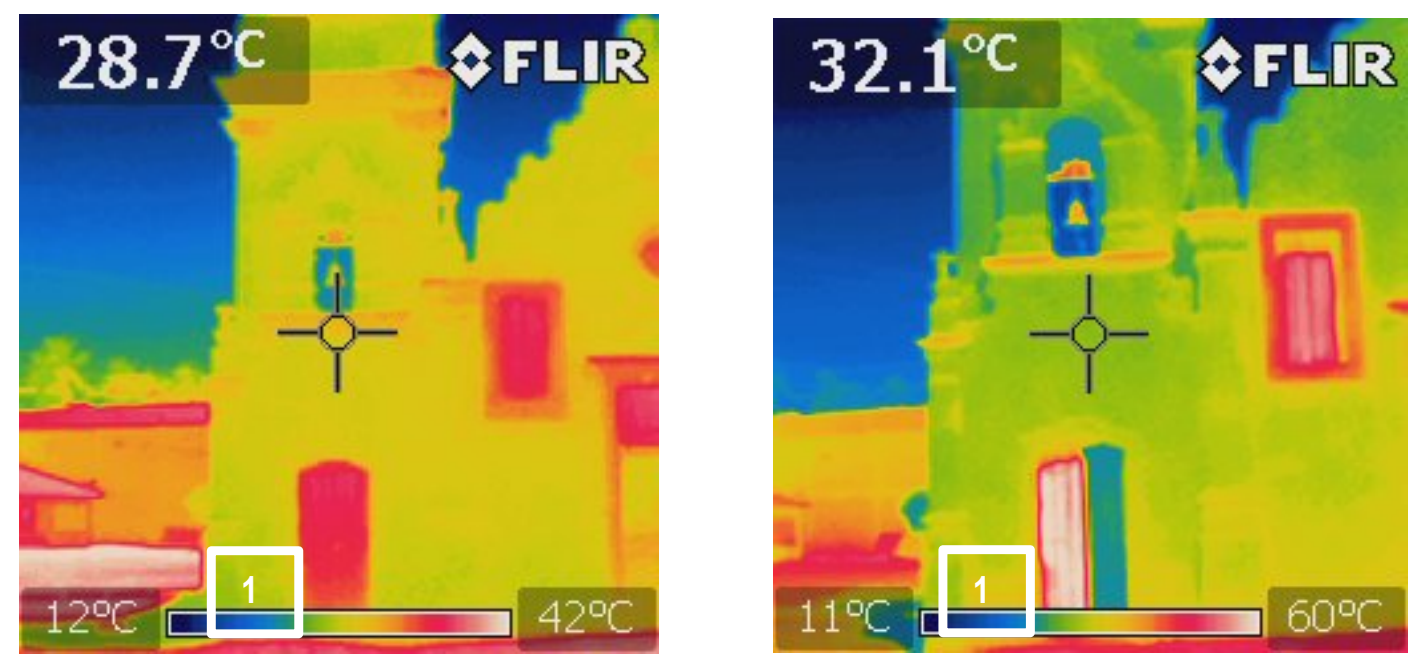

Figura 03 - Termograma da parte esquerda da fachada em período matutino e vespertino, respectivamente. Fonte: Acervo pessoal. 
Registrando termograma com maior proximidade, é possível reduzir a faixa de temperatura e obter maior contraste de cores, sendo possível identificar com maior clareza a região de anomalia térmica.
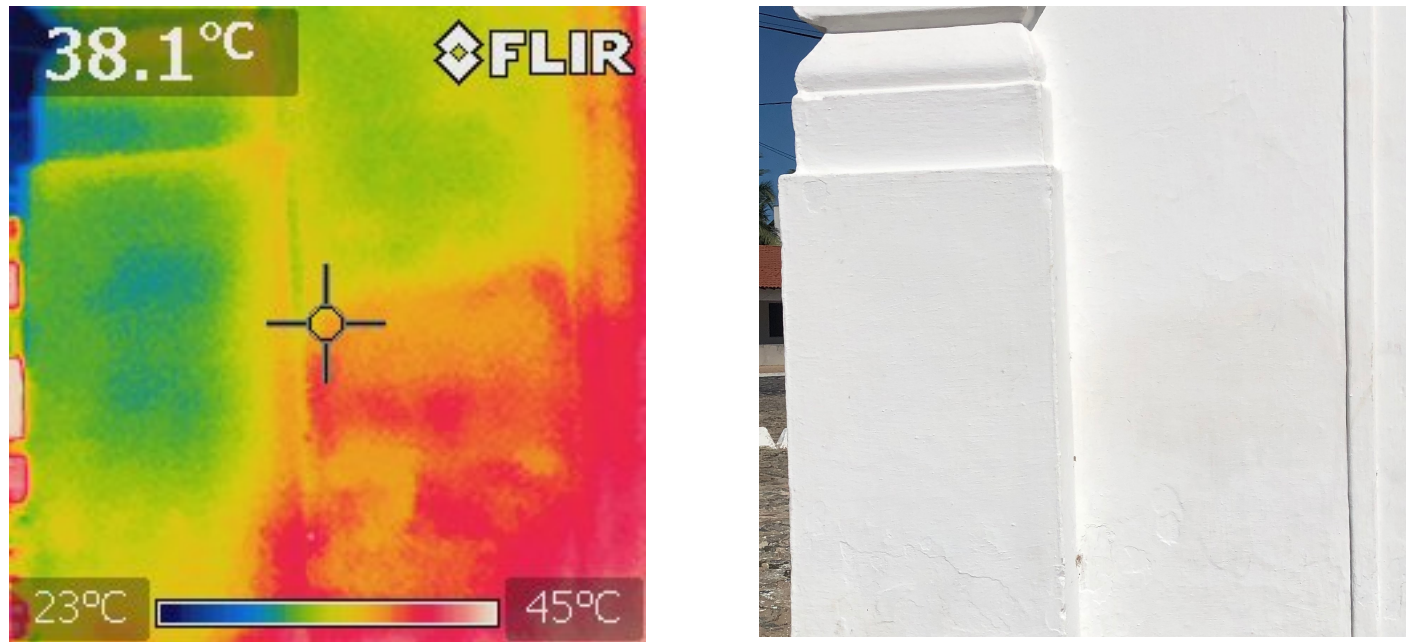

Figura 04 - Detalhe da zona de comportamento térmico divergente em período vespertino. Fonte: Acervo pessoal.

Em inspeção visual identificou-se que a parte inferior da parede lateral estava deteriorada por baixo da pintura podendo ser a responsável pela anomalia térmica que aparece em tom amarelado no termograma da Figura 05. Provavelmente a parede havia recebido recentemente a pintura que é feita anualmente, pois na Figura 06 registrada em outra data, pode-se evidenciar as manchas escuras características da biodeterioração. A presença de agentes microbiológicos pode justificar a área com maior temperatura do termograma.
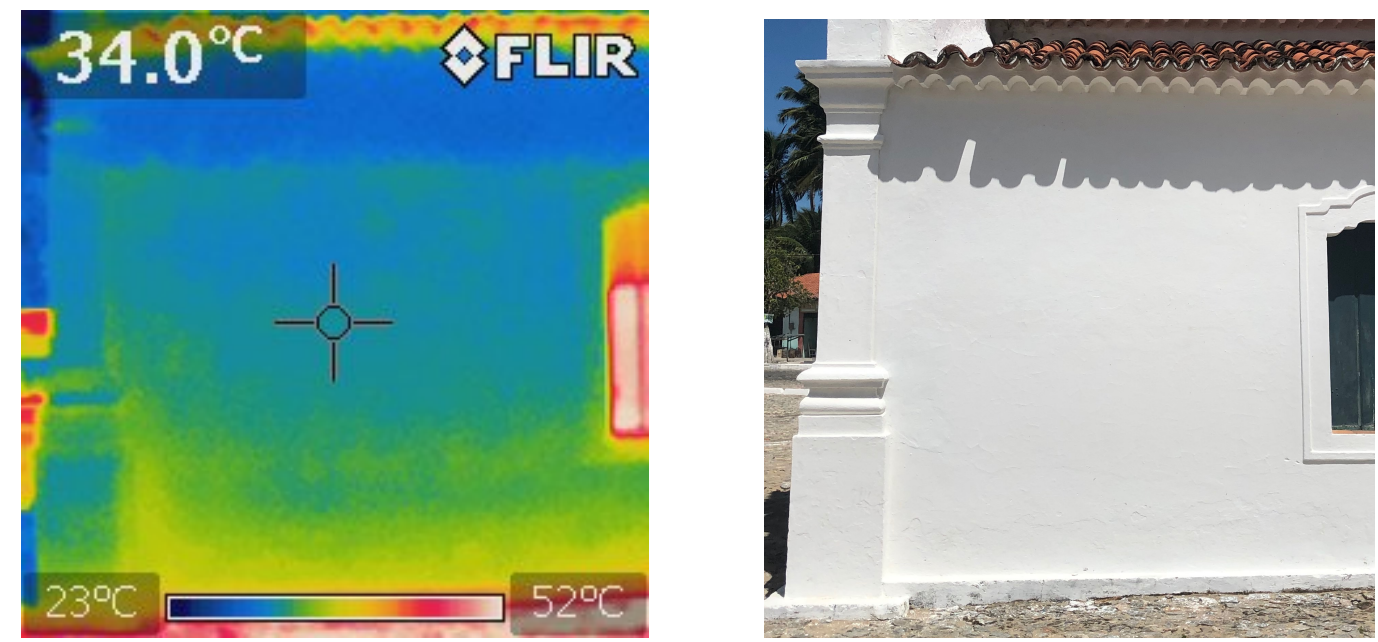

Figura 05 - Termograma e foto de parede externa lateral em período matutino. Fonte: Acervo pessoal.

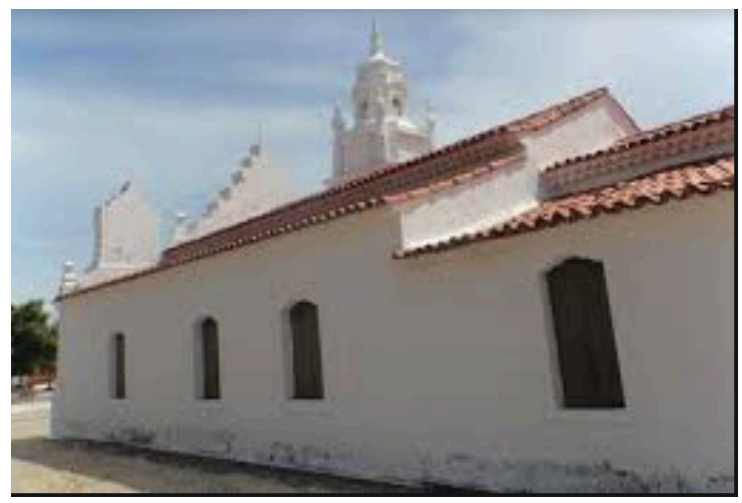

Figura 06 - Área com biodeterioração. Fonte: Coelho e Monteiro et al (2013). 
Nas Figuras 07, é possível perceber que o desgaste na madeira da porta e janela aparece no termograma como zona mais fria, tanto no período da manhã em que a fachada está na sombra, quanto de tarde em que há incidência solar direta.
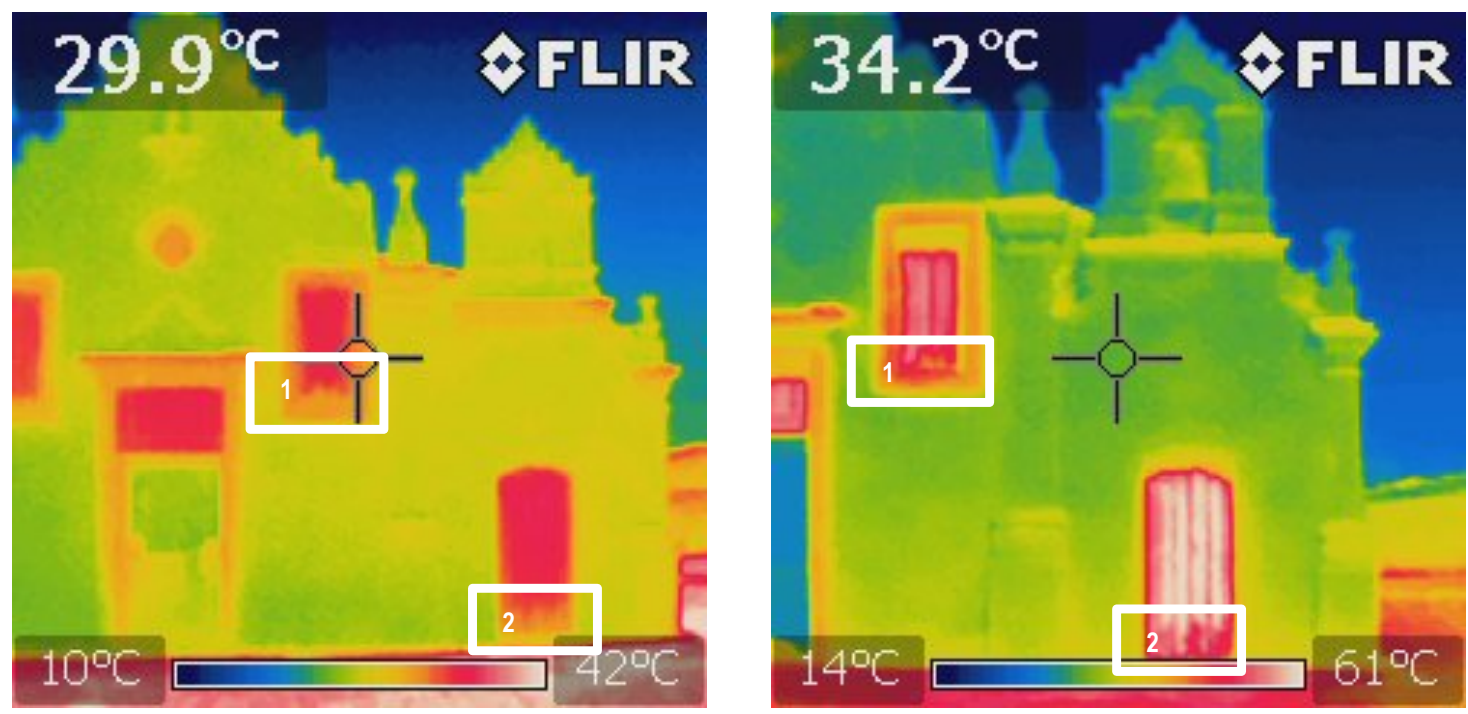

Figura 07 - Termograma da parte direita da fachada em período matutino e vespertino, respectivamente. Fonte: Acervo pessoal.

Na parede posterior da igreja, através de inspeção visual, percebe-se que há zonas com texturas diferentes como consta na Figura 08. Pela situação observada, infere-se que houve desgaste do revestimento, o que demandou manutenção, passando esta área a presentar diferente comportamento térmico. $\mathrm{A}$ área em que houve intervenção aparece como uma zona mais quente. Importante ressaltar que a patologia que gerou o desgaste, como umidade ou descolamento, por exemplo, podem ainda estar presentes, podendo ser também responsáveis pelas manchas amareladas que aparecem no termograma.

Monteiro et al (2015), em seu estudo sobre a conservação da Igreja de Almofala, percebeu o exercício incorreto de técnicas corretivas, que não compatibilizam os materiais originais da construção, como a aplicação de massa corrida, de base cimentícia, em parte da parede sem reboco, sem preparo do local para recebimento do material. Estas técnicas também podem ser responsáveis pelas anomalias térmicas presentes no termograma.
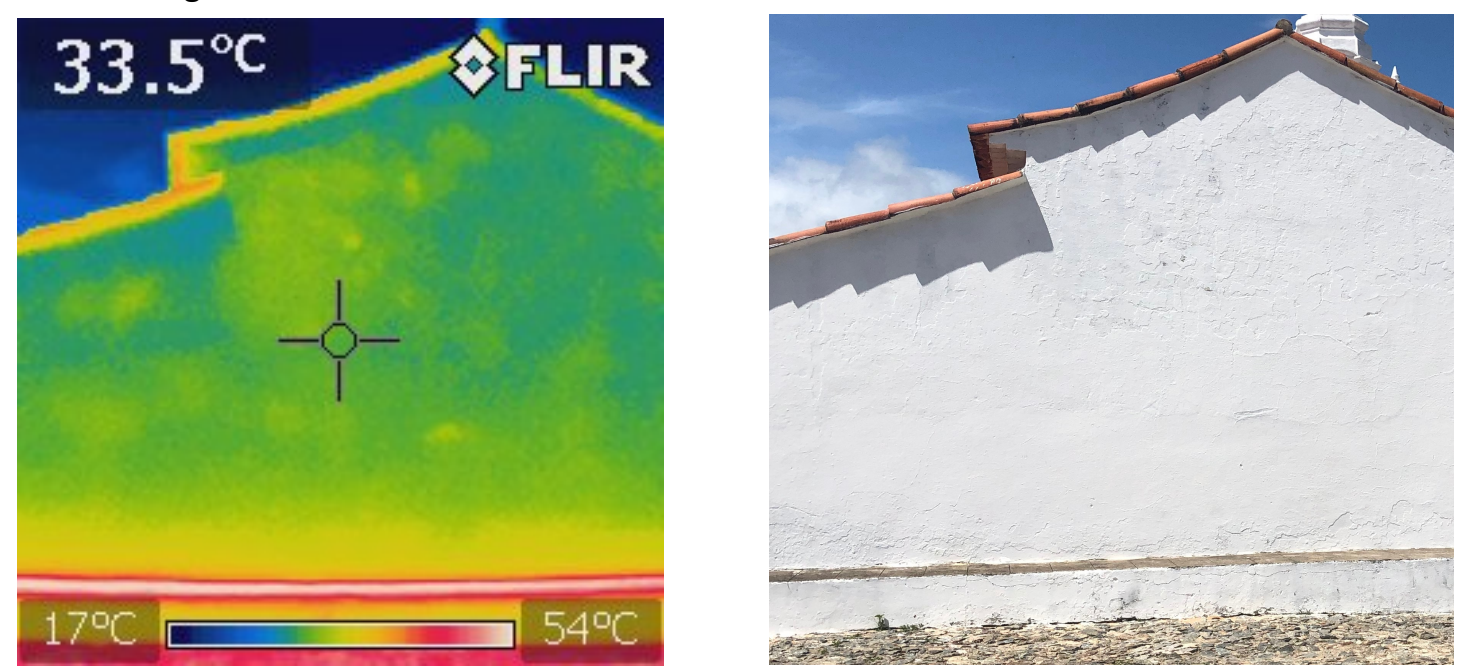

Figura 08 - Termograma e foto de parede externa em período matutino. Fonte: Acervo pessoal.

Analisando a foto da parede interna da igreja representada na Figura 09, não é possível identificar qualquer patologia a olho nu, no entanto, a utilização da câmera termográfica revelou a presença de um zona mais fria. Ao perceber este defeito, como estava na parte inferior, conseguimos verificar que toda a área que 
apareceu em tom amarelo no termograma apresentava ar sob o revestimento, portanto a área verde era a que se encontrava saudável.
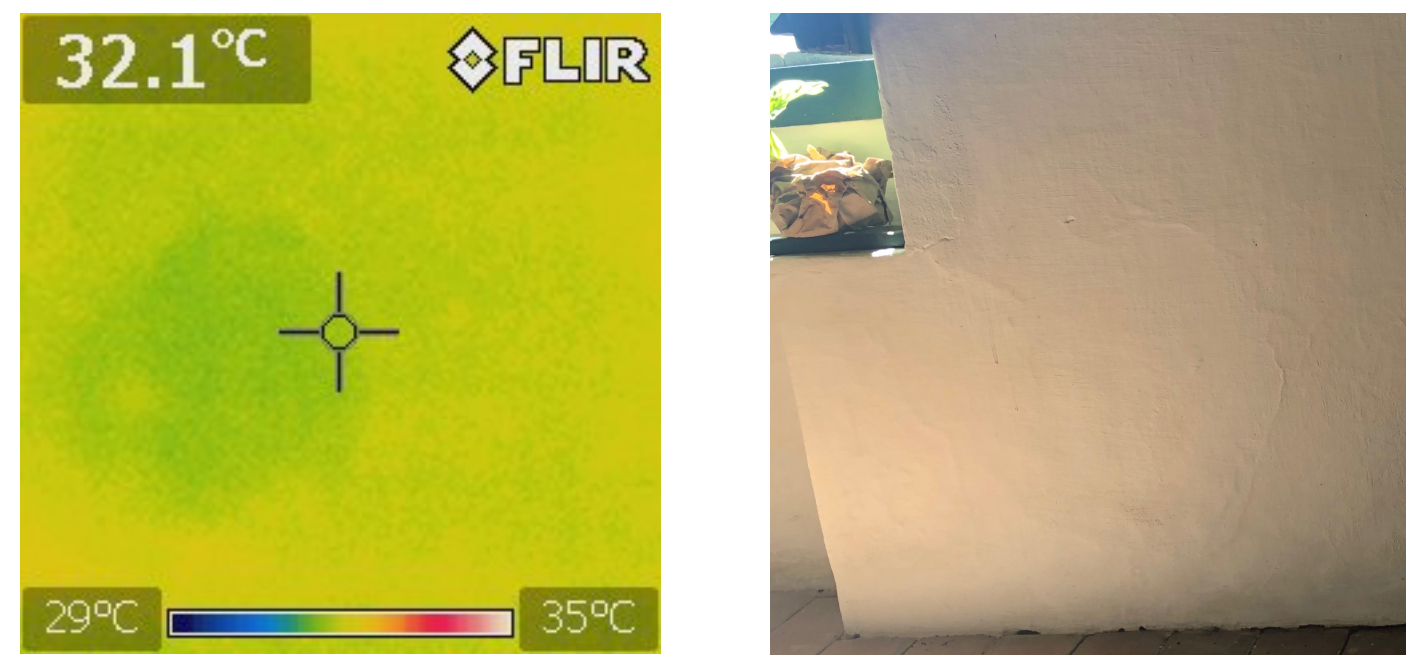

Figura 09 - Termograma e foto de parede interna com descolamento de revestimento. Fonte: Acervo pessoal.

Em outra parede interna em que era possível avistar a olho nu uma mancha escurecida, ao registrar o termograma, esta zona apresentou temperatura mais elevada. Neste caso não foi possível tocar na área destacada para confirmar a presença de descolamento. Se analisarmos de forma análoga ao registro da Figura 09, em que a zona de descolamento apareceu como uma zona mais quente, o descolamento na Figura 10 seria a área de tonalidade amarelada.
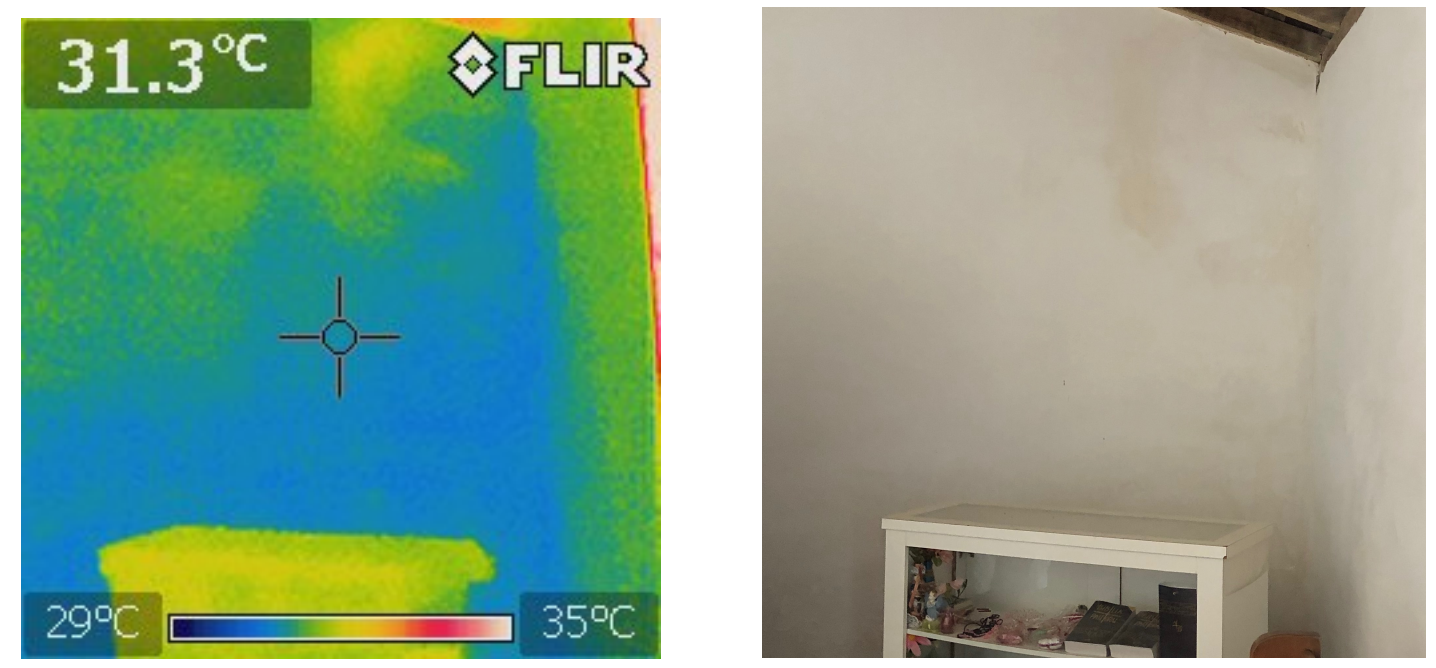

Figura 10 - Termograma e foto de parede interna com mancha. Fonte: Acervo pessoal.

\section{Conclusões}

O ensaio foi feito pelo método de termografia por infravermelho do tipo passiva para obter termogramas de áreas possivelmente comprometidas na Igreja de Nossa Senhora da Conceição de Almofala.

A partir da análise dos resultados obtidos, pela metodologia qualitativa, percebeu-se que a termografia mostra-se como um ensaio adequado para a detecção de algumas patologias, como por exemplo o descolamento do revestimento, umidade e degradação, sendo então possível obter um panorama preliminar da situação da edificação.

Destaca-se, no entanto, que não é possível identificar a gravidade da patologia e que as condições ambientais como sombreamento e incidência solar interferem no ensaio, de forma que as anomalias 
térmicas podem se comportar de maneiras distintas ao longo do dia. Além disso, a falta de conhecimento dos materiais utilizados nas intervenções feitas na edificação e a presença de mais de um tipo de patologia em uma mesma região comprometem a interpretação dos termogramas.

No entanto, apesar das limitações, o método se confirma como um programa promissor para a manutenção preventiva e preditiva de edificações históricas em que não se pode realizar procedimentos invasivos que possam vir a danificar a edificação, uma vez que é possível identificar áreas com anomalias térmicas em que podem vir a emergir algum tipo de patologia.

Então se torna importante realizar outros ensaios, com a finalidade de obter diagnóstico mais seguro. Relevante também obter maiores informações das manutenções que vem sendo efetuadas na edificação de forma que se possa conhecer os materiais e métodos que estão sendo empregados, pois possibilitaria uma interpretação mais precisa dos termogramas.

Sugere-se ainda a realização do ensaio em período noturno, em que há o fluxo reverso do calor, com a finalidade de verificar o comportamento das anomalias térmicas encontradas em diferentes condições de propagação de calor.

\section{Referências Bibliográficas}

ABREU, A. M.; SOARES, I. M.; SOUZA, S. T. O. Termografia em manutenção preditiva: conceitos e aplicabilidades em máquinas e equipamentos industriais. Bolsista de Valor: Revista de divulgação do Projeto Universidade Petrobras e IF Fluminense, Rio de Janeiro, v. 2, n. 1, p. 89-94, [s.d]. 2012.

ASSOCIAÇÃO BRASILEIRA DE NORMAS TÉCNICAS. NBR 15424: Ensaios não destrutivos - Termografia Terminologia. Rio de Janeiro, 2016.

COELHO, Francisco; MONTEIRO, Lívia. A Igreja de Almofala: aspetos históricos e de conservação. In: CONGRESSO IBEROAMERICANO Y XI JORNADA TECNICAS DE RESTAURACION Y CONSERVACION DEL PAGRIMONIO, 3., 2013, [S.I.: s.n.], 2013.

CORTIZO, E. C. Avaliação da técnica de termografia infravermelha para identificação de estruturas ocultas e diagnóstico de anomalias em edificações: Ênfase em Edificações do Patrimônio Histórico. Tese de Doutorado, Departamento de Engenharia Mecânica, UFMG, Belo Horizonte, 2007.

CORTIZO, E. C.; BARBOSA, M. P.; SOUZA, L. A. C. Estado da Arte da Termografia. Fórum Patrimônio: Ambiente Construído e Patrimônio Sustentável, Belo Horizonte, v. 2, n. 2, ago. 2008.

FREITAS, J. G. DE; CARASEK, H.; CASCUDO, O. Utilização de termografia infravermelha para avaliação de fissuras em fachadas com revestimento de argamassa e pintura. Ambiente Construído, Porto Alegre, v. 14, n. 1, p. 57-73, jan./mar. 2014. Disponível em: https://www.scielo.br/pdf/ac/v14n1/v14n1a06.pdf. Acesso em: 10 dezembro 2020.

HOLST, Gerald C. Common Sense approach to thermal imaging. Winter Park (FL): JCD Publishing, 2000. $377 p$.

MONTEIRO, Lívia; SANTOS, David; SANTOS, Esequiel; COELHO, Francisco. A Igreja de Almofala: aspetos históricos e de conservação. [S.I.: s.n.], 2015.

ROCHA, J. H. A.; POVOAS, Y. Detección de delaminaciones en puentes de concreto armado usando Termografía Infrarroja. Revista ingeniería de construcción, Santiago, v.34, n.1, p. 55-64. Abr. 2019. Disponível em: https://scielo.conicyt.cl/pdf/ric/v34n1/0718-5073-ric-34-01-00055.pdf. Acesso em: 18 dezembro 2020.

SILVA, G. P., BATISTA, P. I. B., POVÓAS, Y. V. (2019), "O uso da termografia infravermelha para o estudo do desempenho térmico de paredes: revisão bibliográfica", Revista ALCONPAT, 9 (2), pp. 117 - 129.

TAVARES, S. G. Desenvolvimento de uma metodologia para aplicação de ensaios térmicos não destrutivos na avaliação da integridade de obra de arte. Tese de Doutorado, Departamento de Engenharia Mecânica, UFMG. Belo Horizonte, 2006.

WEATHER. The Weather Channel. Disponível em: https://weather.com. Acesso em: 10 nov. 2020. 